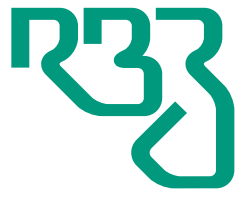

Revista Brasileira de Zootecnia

Brazilian Journal of Animal Science ISSN 1806-9290 www.rbz.org.br

\section{Effect of probiotic Lactobacillus reuteri XC1 coexpressing endoglucanase and phytase on intestinal pH and morphology, carcass characteristics, meat quality, and serum biochemical indexes of broiler chickens}

\author{
Lei Wang ${ }^{1,2}$, Yuzhe Feng ${ }^{1}$, Xiaowei Zhang ${ }^{1}$, Guofang $\mathrm{Wu}^{1,2 *}$ (iD \\ ${ }^{1}$ Qinghai University, Academy of Animal Science and Veterinary Medicine, Xining, China. \\ ${ }^{2}$ Qinghai University, State Key Laboratory of Plateau Ecology and Agriculture, Xining, China.
}

\begin{abstract}
This study investigated the effect of transformed Lactobacillys reuteri on intestinal $\mathrm{pH}$ and morphology, carcass characteristics, meat quality, and serum biochemical indexes of broiler chickens. A total of 480 broilers were assigned to six treatment groups and fed a phosphorus-adequate diet, a phosphorus-deficient diet, or a phosphorus-deficient diet containing different L. reuteri recombinants. The results showed that transformed $L$. reuteri decreased the $\mathrm{pH}$ in the duodenum and jejunum of chickens at day 21, decreased drip loss and cooking loss of muscles, and improved muscle tenderness of chickens at days 21 and 42, but did not affect carcass characteristics and only slightly decreased abdominal fat. Transformed L. reuteri also significantly increased calcium, phosphorus, and glucose levels, decreased the uric acid level of serum at day 21, and significantly increased the glucose level and decreased the triglycerides of serum on day 42. L. reuteri pLEM4159-cel/phy increased the villi height in the duodenum of chickens at days 21 and 42 . The transformed L. reuteri decreased the crypt depth in the duodenum and jejunum of chickens at day 21 and also decreased the crypt depth in the ileum and increased the villi height in the duodenum at day 42. L. reuteri pLEM4158 (phy) and L. reuteri pLEM4159-cel/phy improved the villi height in the ileum at day 42 . Taken together, transformed L. reuteri can improve blood calcium, phosphorus, and glucose metabolism and intestinal development in broilers, but does not affect carcass characteristics.
\end{abstract}

Keywords: bird nutrition, meat quality, microbial additive, phosphorus, $\mathrm{pH}$, villus

\title{
Introduction
}

Glucan and phytic acid (phytate) are two major anti-nutritional factors present in monogastric animal diets that can cause digestion difficulties due to their ability to form insoluble complexes with proteins and minerals in the gastrointestinal tract (GIT). Consequently, their presence in feedstocks can lead to losses in endogenous nutrients that ultimately lead to significant increases in animal feed costs (Humer et al., 2015; Attia et al., 2016; Bueno et al., 2018).

Compared with other cereals, endosperm and aleurone wheat layers contain high levels of high-molecular-weight hydrosoluble arabinoxylan, which can adhere strongly to cell walls to readily form thick granular suspensions. The endosperm cell wall of barley contains abundant glucan that is comprised of multiple $\beta-(1-3)$ and $\beta-(1-4)$ glucosidic bonds (Fernandes et al., 2016), which can produce gel-like materials in the GIT of poultry that can impair intestinal movement. This type of 
gelation can result in significant decrease in the diffusion and action of digestive enzymes, limit systemic absorption of nutrients through the intestinal villi, and stimulate proliferation of spoilage organisms (Attia et al., 2003; Maisonnier et al., 2001).

Phytic acid is a powerful chelating agent that can directly (or indirectly) bind to many nutrients (e.g., minerals, proteins/amino acids, carbohydrates, and lipids), forming phytate complexes (or liposomes) that prevent efficient nutrient absorption (Attia et al., 2003; Attia et al., 2014). The inhibitory action of phytic acid on $\mathrm{Zn}^{2+}$ in the GIT is particularly problematic and can lead to zinc deficiency, dwarfism, and hypogonadism. Acidity is also known to play an important role in determining the stability, solubility, and chelating properties of phytic acid in the gut (Lopez et al., 2002; Gupta et al., 2015).

There are significant concerns about the effect of residual antibiotics, hormones, and other synthetic drugs in meat, egg, and milk products used for human consumption (Attia et al., 2016; Pan et al., 2011; Cabello, 2004; Cabello, 2006). This has resulted in much attention being directed towards identifying alternatives to antibiotic use in livestock, with probiotics having been proposed as a substitute for poultry breeding applications (Stephens et al., 2010; Zhou et al., 2010; Suo et al., 2012). Multifunctional transgenic probiotics have been proposed as a feasible method to overcome problems caused by anti-nutritional factors and antibiotics in animal husbandry. For example, a multifunctional transgenic Lactobacillus reuteri XC1 strain that is capable of degrading $\beta$-glucan and absorbing phytic acid has been evaluated as a probiotic in broilers, with its effect on growth performance, tibia parameters, and the cecum microflora population being investigated. The presence of transformed L. reuteri XC1 was found to improve the feed conversion ratio of broilers from 21 to 42 days; however, no effect on the body weight gain of new-born chicks was observed (Wang et al., 2014).

This study investigates the positive effects of adding transformed L. reuteri XC1 probiotics to the diet of broiler chickens, and reports the beneficial changes in their intestinal $\mathrm{pH}$ and morphology, meat quality, and serum biochemical indexes.

\section{Material and Methods}

Lactobacillus reuteri strain XC1 was isolated from the GIT of healthy broilers. L. reuteri pLEM4156 containing an empty plasmid, L. reuteri pLEM4157 (cel) expressing an endoglucanase gene, L. reuteri pLEM4158 (phy) expressing a phytase gene, and L. reuteri pLEM4159-cel/phy coexpressing endoglucanase and phytase genes were constructed using previously described methods (Wang et al., 2014). Different recombinant $L$. reuteri strains were prepared according to the method described by Mappley et al. (2013).

In total, 480 similarly sized 1-day-old male Arbor Acres (AA) broilers were weighed and randomly assigned to six treatment groups comprising four replicates of 20 birds each. The six groups were offered six dietary treatments of barley-wheat-based diets, which were formulated as isonitrogenous and isoenergetic according to NRC (1994) requirements (Table 1). Control groups were fed a phosphorus-adequate diet (as a positive control) or a phosphorus-deficient diet (as negative control) and were administered distilled water from day 1. Four experimental treatment groups were fed a phosphorus-deficient diet and were administered distilled water containing recombinant $L$. reuteri pLEM4156, L. reuteri pLEM4157 (cel), L. reuteri pLEM4158 (phy), or L. reuteri pLEM4159-cel/phy $\left(2.5 \times 10^{8} \mathrm{cfu} / \mathrm{mL}\right)$ from day 1 . The mixture was provided in the water container, and water was freely accessible to all birds and changed frequently to maintain freshness. Feed and water were supplied for ad libitum intake. Vaccination and light regimens were performed according to routine procedures. Chicks were raised using typical commercial conditions over the 0-42 days of the experiment. All experimental methods and protocols were approved by the local Research Ethics Committee (case no. 2014ZX08008002). The study was conducted in Yangling district (34 $28^{\prime} \mathrm{N}$; $108^{\circ} 07^{\prime}$ E), Xianyang, China.

Two birds were randomly selected at 21 and 42 days old from each replicate and were anesthetized to a surgical plane by an intramuscular injection of xylazine chlorhydrate to minimize suffering, and 
Table 1 - Composition of the experimental diet

\begin{tabular}{lccccc}
\hline & \multicolumn{2}{c}{ Days 1-21 } & & \multicolumn{2}{c}{ Days 22-42 } \\
\cline { 2 - 3 } \cline { 5 - 6 } Item & $\begin{array}{c}\text { Positive } \\
\text { control }\end{array}$ & $\begin{array}{c}\text { Negative } \\
\text { control }\end{array}$ & & $\begin{array}{c}\text { Positive } \\
\text { control }\end{array}$ & $\begin{array}{c}\text { Negative } \\
\text { control }\end{array}$ \\
\hline Composition (g/kg) & & & & & \\
Barley & 390.60 & 382.20 & & 410.00 & 400.00 \\
Wheat & 300.00 & 300.00 & & 310.00 & 287.80 \\
Soybean meal & 180.00 & 200.00 & & 125.40 & 170.50 \\
Fish meal & 65.40 & 52.00 & & 68.70 & 40.00 \\
Soybean oil & 33.90 & 35.40 & & 52.90 & 57.60 \\
Limestone & 10.90 & 14.60 & & 16.00 & 18.50 \\
Dicalcium phosphate & 5.50 & 1.70 & & 2.00 & 1.00 \\
Salt & 1.60 & 1.90 & & 2.80 & 2.10 \\
Choline-Cl (50\%) & 1.00 & 1.00 & & 1.00 & 1.00 \\
Methionine & 1.00 & - & 0.30 & 0.50 \\
Lysine & - & 0.10 & 1.00 & 1.00 \\
Premix ${ }^{1}$ & 10.00 & 10.00 & 10.00 & 10.00 \\
Nutrient level & & & & 300 \\
Metabolizable energy (kcal/kg) & 2900 & 2900 & 3041 & 3041 \\
Crude protein (\%) & 21.00 & 21.00 & 19.00 & 19.00 \\
Calcium (\%) & 0.90 & 0.90 & 0.00 & 0.96 \\
Total phosphorus (\%) & 0.65 & 0.56 & 0.40 & 0.50 \\
Available phosphorus (\%) & 0.45 & 0.35 & & 0.30 \\
\hline
\end{tabular}

${ }^{1}$ The premix provided per kilogram of diets: manganese, $120 \mathrm{mg}$; iron, $100 \mathrm{mg}$; iodine, $0.7 \mathrm{mg}$; zinc, $100 \mathrm{mg}$; selenium, $0.3 \mathrm{mg}$; copper, $8 \mathrm{mg}$; vitamin A, 8,000 IU; vitamin E, $20 \mathrm{IU}$; vitamin $\mathrm{D}_{3}, 1,000 \mathrm{IU}$; flavin, $8.0 \mathrm{mg}$; menadione, $0.5 \mathrm{mg}$; thiamine, $2.0 \mathrm{mg}$; niacin, $35 \mathrm{mg}$; pyridoxine, $3.5 \mathrm{mg}$; biotin, $0.18 \mathrm{mg}$; vitamin $\mathrm{B}_{12}, 0.01 \mathrm{mg}$; pantothenic acid, $10.0 \mathrm{mg}$; antioxidant, $0.4 \mathrm{~g}$; folic acid, $0.55 \mathrm{mg}$ in the phase of $1-21 \mathrm{~d}$, and manganese, $60 \mathrm{mg}$; iron, $60 \mathrm{mg}$; iodine, $0.6 \mathrm{mg}$; zinc, $80 \mathrm{mg}$; selenium, $0.3 \mathrm{mg}$; copper, $8 \mathrm{mg}$; and vitamin A, 6,000 IU; vitamin E, $30 \mathrm{IU}$; vitamin $\mathrm{D}_{3}$, $500 \mathrm{IU}$; flavin, $5.0 \mathrm{mg}$; menadione, $0.5 \mathrm{mg}$; thiamine, $2.0 \mathrm{mg}$; niacin, $30 \mathrm{mg}$; pyridoxine, $3.0 \mathrm{mg}$; biotin, $0.15 \mathrm{mg}$; vitamin $\mathrm{B}_{12}, 0.01 \mathrm{mg}$; pantothenic acid, $10.0 \mathrm{mg}$; antioxidant, $0.5 \mathrm{~g}$; folic acid, $0.55 \mathrm{mg}$ in the phase of $22-42 \mathrm{~d}$.

their duodenums, jejunums, and ileums were then surgically removed. The $\mathrm{pH}$ of the contents of each intestinal segment at three different points was determined using a handheld digital display $\mathrm{pH}$ meter. A 2-5 cm segment from the middle of each intestinal sample was dissected, its enteric cavity was washed with physiological saline, the sample was then fixed with $4 \%$ paraformaldehyde for $12 \mathrm{~h}$, gradient dehydrated by $20 \%$ and $30 \%$ sucrose for 1 day, then dried on absorbent paper towel. Then, the intestinal sample was trimmed to the appropriate size, placed on an object stage, and embedded in $100 \%$ optimal cutting temperature compound. Frozen embedded samples were serially sectioned at $10-\mu \mathrm{m}$ thickness along the cross-section (three cross-sections from each sample), and then fixed on slides, and stained with hematoxylin and eosin. Photomicrographs of the intestinal slides were obtained using an Eclipse E200 microscope (Nikon, Tokyo, Japan) equipped with a Motic 2300 capture system (Sony Super Steady Shot, 9.1 megapixels). A total of 10 intact, well-oriented crypt-villus units from each cross-section were selected and analyzed using Image ProPlus software (Version 4.5.0.29, 2001). Measurement of the villus height and crypt depths was performed according to the method of Villanueva et al. (2016).

Another two birds of 42 days old from each replicate were randomly chosen and after 10 -h of overnight fasting, were anesthetized as previously described. Their carcasses were defeathered and weighed, with subsequent treatment of their semi-eviscerated and fully eviscerated carcasses using the method described by Mosca et al. (2016). Their left breasts (and associated tightly bound abdominal fat) were weighed to calculate the dressing percentages, semi-eviscerated yields, fully eviscerated yields, breast percentages, tight percentages, and abdominal fat percentages. Simultaneously, their right breasts were used to determine meat quality ( $\mathrm{pH}$, drainage percentage, drip loss, cooking loss, and shear force) using the assay methods described by Choo et al. (2014). 
Blood samples ( $5 \mathrm{~mL}$ ) were collected from the brachial veins of two birds from each replicate after 21 and 42 days, which were then centrifuged at $3000 \mathrm{rpm}$ for $5 \mathrm{~min}$ to obtain serum samples that were stored at $-20^{\circ} \mathrm{C}$. Serum concentrations of urea nitrogen, calcium, phosphorus, glucose, total cholesterol, and uric acid were determined using a clinical chemistry analyzer (Gilford Impact 400E, Gilford Systems, Oberlin, OH, USA).

Each replicate was considered as the experimental unit. The data were analyzed by one-way ANOVA and Duncan's multiple range test (Dawson and Trapp, 2001), using the General Linear Model of the SPSS22.0 software (SPSS Inc., Chicago, IL, USA). The significance level was taken as $\mathrm{P}<0.05$. The statistical model was as follows:

$$
\mathrm{Y}_{\mathrm{ij}}=\mu+\mathrm{G}_{\mathrm{i}}+\varepsilon_{\mathrm{ij}}
$$

in which $Y_{i j}=$ observed value of the dependent variables, $\mu$ = overall mean, $G_{i}=$ effect of presence or absence of different transformed L. reuteri, and $\varepsilon_{i j}=$ random error associated with each observation.

\section{Results}

Broilers were fed a barley-wheat-based diet containing transformed L. reuteri strains, and changes in the $\mathrm{pH}$ of their intestinal tracts were monitored over time (Figure 1). At day 21, the $\mathrm{pH}$ values of duodenums and jejunums of chicks that received L. reuteri pLEM4156, L. reuteri pLEM4157 (cel), L. reuteri pLEM4158 (phy), or L. reuteri pLEM4159-cel/phy were significantly lower than those of the positive and negative control groups $(\mathrm{P}<0.05)$. However, there were no significant differences in the $\mathrm{pH}$ values or the duodenums, jejunums, and ileums of birds fed the different treatments at day $42(\mathrm{P}>0.05)$.

No significant differences in carcass composition were found in chicks fed different treatments at day 42 (Table 2), although they all exhibited slightly decreased abdominal fat levels ( $\mathrm{P}>0.05)$ relative to the control groups. Amongst them, chickens treated with L. reuteri pLEM4159-cel/phy had the lowest abdominal fat content. Compared with the control group, all treatment groups exhibited no significant differences in $\mathrm{pH}$ and drainage rates $(\mathrm{P}>0.05)$. However, there were significant decreases in drip losses, cooking losses, and shear force, as well as an improvement in overall intramuscular quality $(\mathrm{P}<0.05)$.

The use of $L$. reuteri pLEM4159-cel/phy resulted in a significant increase in the duodenum villus height of chicks at day $21(\mathrm{P}<0.05)$ (Figure 2). Supplementation with L. reuteri pLEM4158 (phy), L. reuteri pLEM4159-cel/phy, or L. reuteri pLEM4157 (cel) resulted in a significant decrease in duodenum crypt

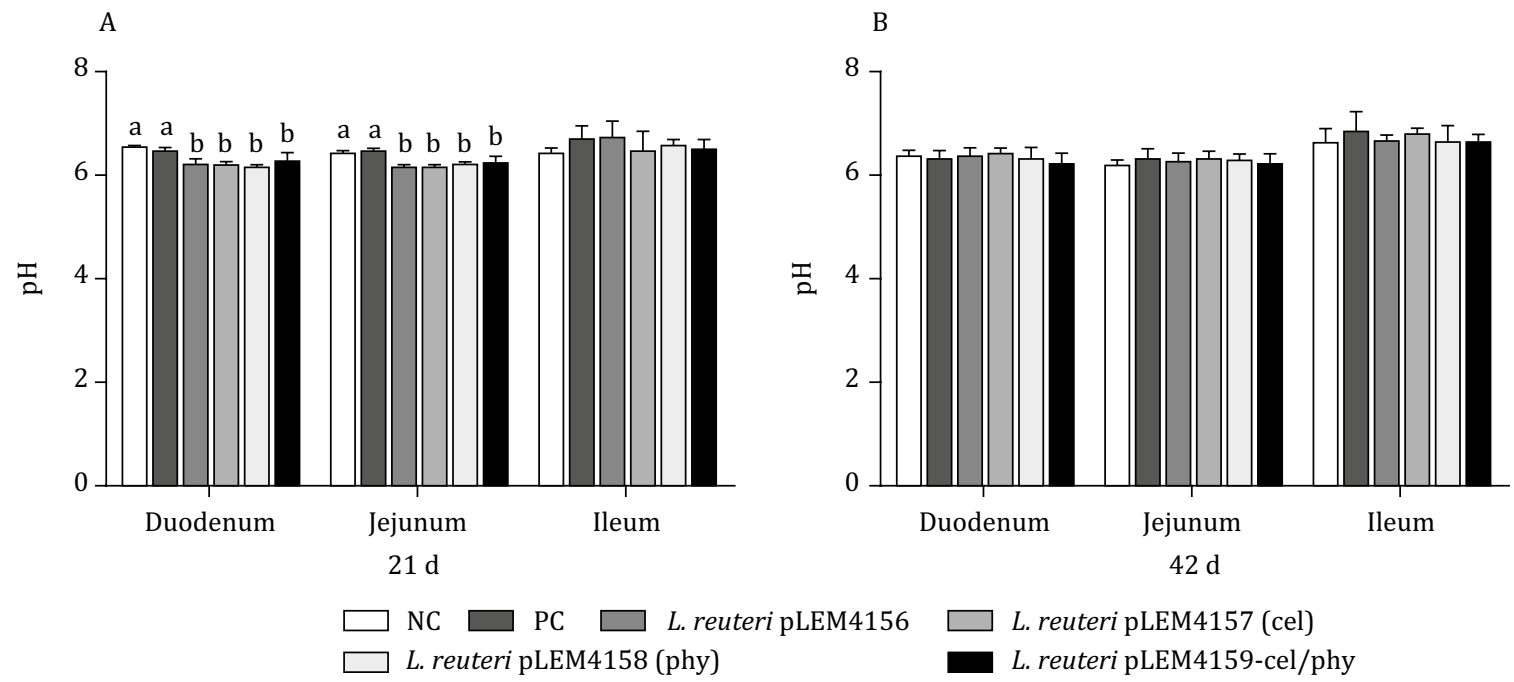

A: $\mathrm{pH}$ in the small intestine of broilers at day 21; $\mathrm{B}: \mathrm{pH}$ in the small intestine of broilers at day 42 .

NC - negative control; PC - positive control.

Data are expressed as mean $\pm \mathrm{SD}$.

$\mathrm{a}, \mathrm{b}$ - Means on the error bar with different letters are significantly different $(\mathrm{P}<0.05)$.

Figure 1 - Effects of transformed L. reuteri strain supplementation on intestinal tract $\mathrm{pH}$ of broilers. 
Table 2 - Effects of transformed L. reuteri strain supplementation on carcass characteristics and meat quality of broilers

\begin{tabular}{lcccccccc}
\hline & \multicolumn{7}{c}{ Control group } & \multicolumn{7}{c}{ L. reuteri group } & & \\
\cline { 2 - 7 } Carcass characteristic & NC & PC & pLEM4156 & $\begin{array}{c}\text { pLEM4157 } \\
\text { (cel) }\end{array}$ & $\begin{array}{c}\text { pLEM4158 } \\
\text { (phy) }\end{array}$ & pLEM4159-cel/phy & SEM $^{1}$ & P-value \\
\hline Live weight (kg) & 2.04 & 2.20 & 1.99 & 2.13 & 2.22 & 2.14 & 0.038 & 0.552 \\
Carcass weight (kg) & 1.88 & 2.07 & 1.84 & 1.98 & 2.06 & 1.98 & 0.036 & 0.360 \\
Dressing percentage (\%) & 92.11 & 93.78 & 92.20 & 93.13 & 92.63 & 92.80 & 0.240 & 0.373 \\
Semi-eviscerated yield (\%) & 85.93 & 87.12 & 86.46 & 86.17 & 86.79 & 87.01 & 0.269 & 0.802 \\
Fully eviscerated yield (\%) & 69.23 & 72.54 & 69.58 & 71.12 & 71.67 & 71.91 & 0.440 & 0.171 \\
Breast (\%) & 12.27 & 11.27 & 11.53 & 12.20 & 11.39 & 11.86 & 0.195 & 0.602 \\
Thighs (\%) & 13.06 & 12.79 & 13.29 & 13.29 & 14.24 & 13.74 & 0.253 & 0.675 \\
Abdominal fat (\%) & 6.77 & 6.76 & 6.11 & 6.05 & 6.43 & 5.81 & 0.301 & 0.940 \\
Meat quality & & & & & & & & \\
pH 45 min & 5.87 & 6.11 & 6.05 & 6.08 & 6.26 & 6.05 & 0.058 & 0.655 \\
pH 24 h & 5.32 & 5.29 & 5.38 & 5.53 & 5.52 & 5.37 & 0.039 & 0.392 \\
Drainage (\%) & 32.72 & 32.83 & 32.23 & 31.32 & 30.54 & 31.47 & 0.529 & 0.857 \\
Drip loss (\%) & 4.63 & 4.69 & 3.68 & 3.75 & 3.31 & 3.13 & 0.197 & 0.094 \\
Cooking loss (\%) & $25.77 \mathrm{a}$ & $25.74 \mathrm{a}$ & $21.65 \mathrm{~b}$ & $22.64 \mathrm{~b}$ & $20.39 \mathrm{~b}$ & $20.45 \mathrm{~b}$ & 0.629 & 0.008 \\
Shear force (N) & $49.49 \mathrm{a}$ & $42.92 \mathrm{a}$ & $33.34 \mathrm{~b}$ & $34.38 \mathrm{~b}$ & $30.10 \mathrm{~b}$ & $29.60 \mathrm{~b}$ & 2.196 & 0.028 \\
\hline
\end{tabular}

NC - negative control; PC - positive control.

a,b,c - Means within the same row with different letters are significantly different $(\mathrm{P}<0.05)$.

${ }^{1} \mathrm{SEM}$ - pooled standard error of the mean $(n=8$ birds for each replicate).
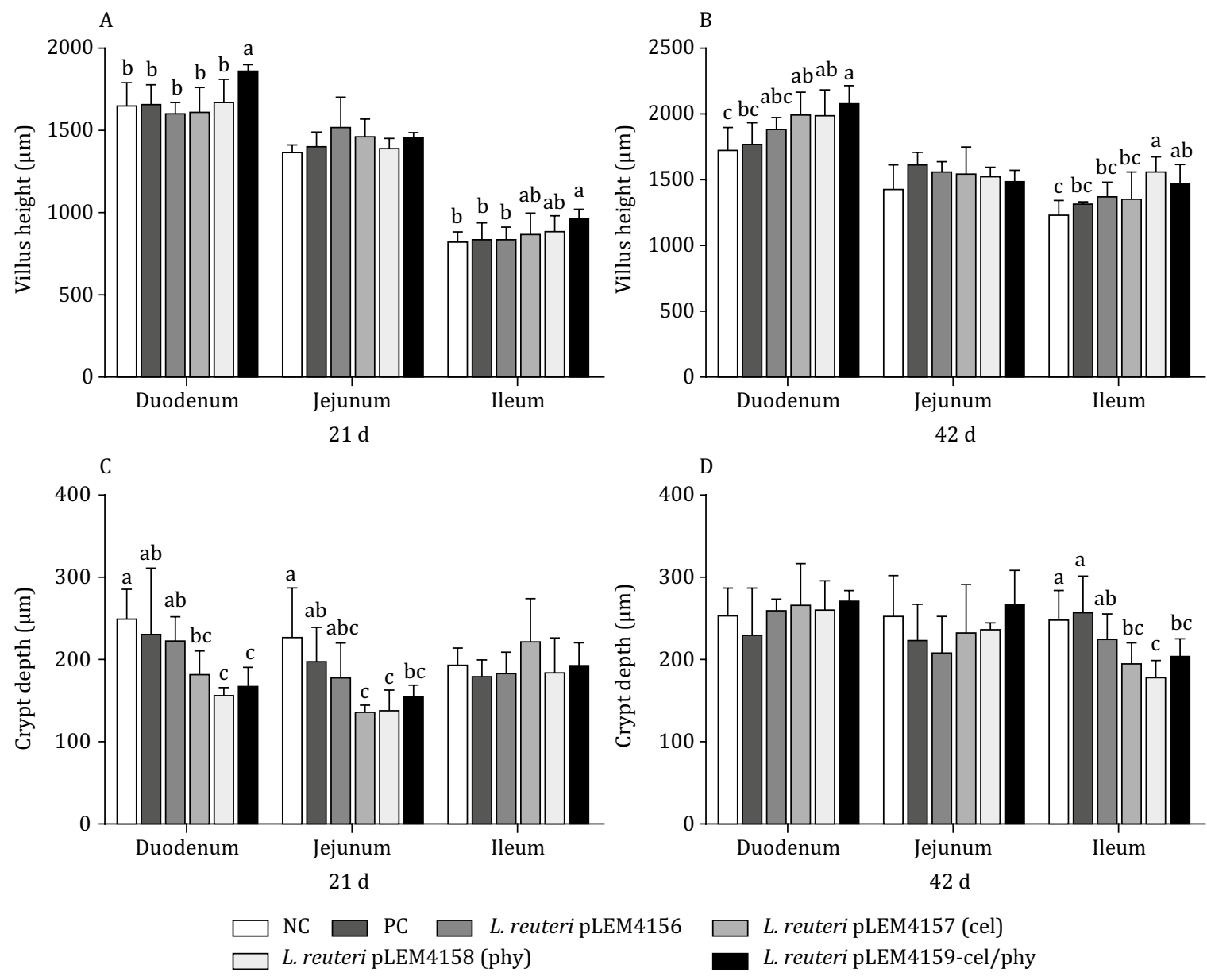

A: villus height in the small intestine of broilers at day 21; B: villus height in the small intestine of broilers at day 42; C: crypt depth in the small intestine of broilers at day 21; D: crypt depth in the small intestine of broilers at day 42.

NC - negative control; PC - positive control.

Data are expressed as the mean \pm SD.

a,b,c - Means on the error bar with different letters are significantly different $(\mathrm{P}<0.05)$.

Figure 2 - Effects of transformed L. reuteri strain supplementation on intestinal villus height and crypt depth of broilers. 
depth at day $21(\mathrm{P}<0.05)$. The duodenum crypt depth of chicks treated with L. reuteri pLEM4158 (phy) or L. reuteri pLEM4159-cel/phy at day 21 were significantly lower than of those treated with L. reuteri pLEM4156 and of the positive control group $(\mathrm{P}<0.05)$.

No notable differences in jejunum villus height were observed for the chicks fed different treatments at day 21. However, supplementation with L. reuteri pLEM4158 (phy), L. reuteri pLEM4159-cel/phy, or L. reuteri pLEM4157 (cel) significantly decreased crypt depth in the jejunum at day $21(\mathrm{P}<0.05)$. Supplementation with $L$. reuteri pLEM4159-cel/phy significantly increased the ileum villus height of chicks at day $21(\mathrm{P}<0.05)$; however, there was no significant effect on the ileum crypt depth at day 21 for all other treatment groups $(\mathrm{P}<0.05)$. Compared with the negative control group, supplementation with L. reuteri pLEM4158 (phy), L. reuteri pLEM4159-cel/phy, or L. reuteri pLEM4157 (cel) resulted in a significant increase in duodenum villus height at day $42(\mathrm{P}<0.05)$. However, no significant effects on the ileal crypt depth, jejunal villus height, and crypt depth of chicks fed different treatments at day 42 were observed $(\mathrm{P}>0.05)$. Compared with the positive and negative control groups, supplementation with L. reuteri pLEM4158 (phy) or L. reuteri pLEM4159-cel/phy significantly increased the villus height of the ileum of chicks at day $42(\mathrm{P}<0.05)$. Analogously, supplementation with L. reuteri pLEM4158 (phy), L. reuteri pLEM4159-cel/phy, or L. reuteri pLEM4157 (cel) significantly decreased ileum crypt depth at day $42(\mathrm{P}<0.05)$.

No significant differences in urea nitrogen, total cholesterol, or triglyceride levels were observed in the serum of chicks fed different treatments at day $21(\mathrm{P}>0.05)$ (Table 3$)$. The calcium content of serum from chicks treated with L. reuteri pLEM4159-cel/phy, L. reuteri pLEM4156, L. reuteri pLEM4157 (cel), or L. reuteri pLEM4158 (phy) were all significantly higher after 21 days. The phosphorus content of serum of chicks treated with L. reuteri pLEM4158 (phy), L. reuteri pLEM4159-cel/phy, L. reuteri pLEM4156, or L. reuteri pLEM4157 (cel) was also greater $(\mathrm{P}<0.05)$. The glucose content of serum in chicks treated with L. reuteri pLEM4157 (cel) or L. reuteri pLEM4159-cel/phy at day 21 was significantly higher than that of chicks treated with L. reuteri pLEM4156 or chicks in the negative and positive control groups $(\mathrm{P}<0.05)$. There were no significant differences in urea nitrogen, calcium,

Table 3 - Effects of transformed L. reuteri strain supplementation on serum biochemical indexes (SBI; mmol/L)

\begin{tabular}{|c|c|c|c|c|c|c|c|c|}
\hline \multirow[b]{2}{*}{ SBI } & \multicolumn{2}{|c|}{ Control group } & \multicolumn{4}{|c|}{ L. reuteri group } & \multirow[b]{2}{*}{ SEM $^{1}$} & \multirow[b]{2}{*}{ P-value } \\
\hline & NC & $\mathrm{PC}$ & pLEM4156 & $\begin{array}{l}\text { pLEM4157 } \\
\text { (cel) }\end{array}$ & $\begin{array}{l}\text { pLEM4158 } \\
\text { (phy) }\end{array}$ & pLEM4159-cel/phy & & \\
\hline \multicolumn{9}{|c|}{ Day 21} \\
\hline BUN & 0.37 & 0.29 & 0.33 & 0.30 & 0.28 & 0.35 & 0.017 & 0.734 \\
\hline $\mathrm{Ca}$ & $1.61 \mathrm{c}$ & $1.69 \mathrm{bc}$ & $2.05 \mathrm{ab}$ & $2.01 \mathrm{ab}$ & $2.09 \mathrm{ab}$ & $2.32 \mathrm{a}$ & 0.071 & 0.014 \\
\hline $\mathrm{P}$ & $1.34 \mathrm{c}$ & $1.57 \mathrm{bc}$ & $1.75 b$ & $1.85 b$ & $2.33 \mathrm{a}$ & $2.22 \mathrm{a}$ & 0.093 & 0.001 \\
\hline GLU & $9.27 \mathrm{~b}$ & $10.38 \mathrm{~b}$ & $10.06 \mathrm{~b}$ & $13.14 \mathrm{a}$ & $10.74 \mathrm{ab}$ & $14.00 \mathrm{a}$ & 0.420 & 0.000 \\
\hline $\mathrm{TC}$ & 3.25 & 3.33 & 3.60 & 3.91 & 3.44 & 3.48 & 0.193 & 0.957 \\
\hline TG & 0.47 & 0.43 & 0.45 & 0.36 & 0.43 & 0.35 & 0.022 & 0.574 \\
\hline UA & $0.34 \mathrm{a}$ & $0.32 \mathrm{ab}$ & $0.25 \mathrm{abc}$ & $0.21 \mathrm{c}$ & $0.25 b c$ & $0.19 c$ & 0.015 & 0.013 \\
\hline \multicolumn{9}{|c|}{ Day 42} \\
\hline BUN & 0.33 & 0.29 & 0.28 & 0.36 & 0.45 & 0.27 & 0.025 & 0.312 \\
\hline $\mathrm{Ca}$ & 2.57 & 2.53 & 2.53 & 2.55 & 2.43 & 2.57 & 0.052 & 0.973 \\
\hline $\mathrm{P}$ & 2.33 & 2.57 & 2.20 & 2.46 & 2.40 & 2.31 & 0.055 & 0.505 \\
\hline GLU & $5.71 \mathrm{c}$ & $6.81 \mathrm{bc}$ & $8.56 \mathrm{ab}$ & $10.33 a$ & 8.89ab & $10.06 \mathrm{a}$ & 0.472 & 0.004 \\
\hline TC & 3.44 & 4.07 & 3.31 & 2.99 & 3.33 & 3.41 & 0.122 & 0.282 \\
\hline $\mathrm{TG}$ & $0.56 \mathrm{a}$ & $0.50 \mathrm{a}$ & $0.45 \mathrm{ab}$ & $0.51 \mathrm{ab}$ & $0.47 \mathrm{ab}$ & $0.40 \mathrm{~b}$ & 0.016 & 0.045 \\
\hline UA & 0.28 & 0.31 & 0.26 & 0.24 & 0.24 & 0.27 & 0.061 & 0.862 \\
\hline
\end{tabular}

NC - negative control; PC - positive control; BUN - blood urea nitrogen; GLU - glucose; TC - total cholesterol; TG - triglyceride; UA - uric acid. a,b,c - Means within the same row with different letters are significantly different $(\mathrm{P}<0.05)$.

${ }^{1} \mathrm{SEM}$ - pooled standard error of the mean ( $\mathrm{n}=8$ birds for each replicate). 
phosphorus, total cholesterol, and uric acid in the serum of chicks fed different treatments at day 42 $(\mathrm{P}>0.05)$. However, the glucose content of the serum of chicks treated with L. reuteri pLEM4157 (cel) or L. reuteri pLEM4159-cel/phy was greater than of chicks in the negative and positive control groups $(\mathrm{P}<0.05)$. The glucose content of the serum of chicks treated with $L$. reuteri pLEM4156 or L reuteri pLEM4158 (phy) was higher than of chicks in the negative control group $(\mathrm{P}<0.05)$. Supplementation with $L$. reuteri pLEM4159-cel/phy was found to decrease the triglyceride content of serum in chicks at day $42(\mathrm{P}<0.05)$.

\section{Discussion}

The small intestine is the main site of nutrient absorption, with intestinal morphology, structure, and function determining the rate of nutrient absorption (Xu et al., 2003). Villus height and width, crypt depth, villus height:crypt depth ratio (VH:CD), and mucosal/muscle layer thickness in the small intestine are all important factors affecting the rate of nutrient absorption. Villus height and width determine the contact area with nutrients, with thinner, shorter villi normally resulting in reduced absorption capacity (Santin et al., 2001; Montagne et al., 2003).

Zhang et al. (2005) previously reported that administration of Saccharomyces cerevisiae to the diets of broilers can increase their VH:CD ratio. Lei et al. (2015) reported that birds fed Bacillus amyloliquefaciens showed significantly increased villus height, crypt depth, and VH:CD ratio of the small intestine on day 21. Al-Sultan et al. (2016) found that probiotics increased villus length and decreased crypt depth in the small intestine of broilers. Mathlouthi et al. (2002) reported that the addition of xylanase improved the morphology of the ileal villi, leading to increased VH:CD ratio. $\mathrm{Wu}$ et al. (2004) reported that supplementation with microbial phytase increased villus height in the duodenum and reduced the number of goblet cells present in the jejunum, with xylanase supplementation causing an increase in goblet cell numbers in the duodenum and decreased crypt depths in the jejunum. Administration of both enzymes increased villus height in the ileum and crypt depths in the jejunum and ileum.

Jaroni et al. (1999) reported that feeding chickens a wheat diet resulted in the formation of short villi in the jejunum that were thick and atrophic. Conversely, Iji et al. (2001) reported that high wheat diets had no effect on the small intestine morphology of broilers. In the present study, the addition of $L$. reuteri pLEM4159-cel/phy was found to increase villus height in the duodenum of chickens at days 21 and 42 , whereas the administration of L. reuteri pLEM4158 (phy), L. reuteri pLEM4159-cel/phy, or $L$. reuteri pLEM4157 (cel) resulted in decreased crypt depths in their duodenums and jejunums at day 21. The use of these probiotics also led to decreased ileum crypt depths and increased duodenal villus heights at day 42. L. reuteri pLEM4158 (phy) or L. reuteri pLEM4159-cel/phy supplementation led to improved villus height in the ileum of chickens at day 42.

The administration of exogenous enzymes is known to result in changes in bacterial activity in the GIT that can lead to changes in the morphology and composition of microflora (Attia et al., 2014). These exogenous enzymes produce monosaccharides and oligosaccharides in the intestine that are known to promote the growth of beneficial bacteria that can improve animal growth (Galdeano et al., 2007).

In the current study, supplementation of a barley-wheat-based diet with transformed L. reuteri strains was found to significantly increase calcium, phosphorus, and glucose levels and decrease uric acid levels in serum at day 21 , whilst further increasing glucose levels and decreasing the triglyceride content at day 42 .

It has been suggested that transformed L. reuteri can secrete phytase, endoglucanase, and organic acids to influence the electrolyte ( $\mathrm{Ca}, \mathrm{P}$ ), glucose, and lipid composition of the blood of the host. Phytase can directly hydrolyze the phosphate groups of phytate, whilst cellulolytic enzymes hydrolyze oligosaccharides to decrease chymous viscosity (Attia et al., 2014). The action of these digestive enzymes can combine to facilitate increased host digestive enzyme activity. The presence of organic 
acids in the diet results in a lower $\mathrm{pH}$ environment in the gut, which can result in decreased stability and increased solubility of chelating phytate. However, Aureli et al. (2011) reported that supplementation of phosphorus-deficient diets with microbial phytase had no significant effect on serum calcium and glucose, although a significant increase in the blood phosphorus concentration and a decrease in blood uric acid levels was observed. Kies et al. (2005) found that supplementation with phytase resulted in a significant increase in blood glucose and phosphorus levels, with no effect on blood calcium levels in piglets.

However, Mondal et al. (2007) showed that phytase supplementation of a low-phosphorus diet could increase blood phosphorus and calcium concentration levels in broilers, with no changes observed in their blood glucose and cholesterol levels. Kashani et al. (2014) reported that supplementation of low-protein diets with phytase resulted in increased total cholesterol and triglycerides levels in the serum of laying hens. Liu et al. (2009) reported that supplementation of a low-phosphorus diet with phytase increased total blood cholesterol levels of broilers. Balamurugan and Chandrasekaran (2010) found that combined administration of non-starch polysaccharides hydrolyzing enzyme and phytase improved the blood glucose levels of broilers. Józefiak et al. (2010) reported that supplementation with multi-carbohydrase and phytase had no significant effect on the total cholesterol and glucose levels in the blood of broilers. Cowieson et al. (2013) observed that addition of microbial phytase and myo-inositol to wheat/corn-based diets resulted in increased blood glucose levels and decreased total blood cholesterol and triglyceride levels in broilers. Mansoub (2010) and Pourakbari et al. (2016) found that probiotic supplementation led to lower triglyceride and cholesterol concentrations in the serum of broilers. Kalavathy et al. (2003) also showed that a diet supplemented with Lactobacillus culture could significantly decrease the levels of total cholesterol and triglycerides in the blood of broilers.

In our study, no differences in carcass characteristics were observed in broilers in all of the treatment groups, which was in agreement with previous studies on the effects of yeast (Attia et al., 2014) and probiotics (Pourakbari et al., 2016) supplementation. The overall quality of broilers produced was directly related to their growth performance, especially their live weight. All treatment groups displayed a tendency towards slightly decreased abdominal fat content, consistent with lower triglyceride and cholesterol blood levels leading to reduced abdominal fat deposition (Anjum et al. 2005; Mehr et al., 2007).

Meat quality is related to pre- and post-slaughter practices, age, strain and sex of the bird, and the environment and nutrition that the bird is exposed to during rearing (Attia et al., 2014). Shear force and drip loss tests are important indicators used to estimate the texture, tenderness, water-holding capacity, and juiciness of chicken meat (Rasmussen and Andersson, 1996). The addition of L. reuteri to the diet resulted in improved intramuscular quality that led to significant decrease in drip and weight losses during cooking. Zhou et al. (2010) previously reported that supplementation with Bacillus coagulans ZjU0616 improved resistance to shear force in chicken breast. Mehr et al. (2007) observed that a high level of probiotic supplementation resulted in higher body and carcass weights and breast percentages in broilers. However, Zhang et al. (2005) reported that S. cerevisiae had no beneficial effects on shear force resistance in male broiler breast muscle.

\section{Conclusions}

This study showed that supplementation of broiler diets with transformed L. reuteri results in improved blood calcium and phosphorus levels, accompanied by better overall glucose metabolism and intestinal development. However, it revealed that short-term feeding with transformed L. reuteri does not improve carcass morphology or meat quality in broilers.

\section{Conflict of Interest}

The authors declare no conflict of interest. 


\section{Author Contributions}

Data curation: Y. Feng. Methodology: X. Zhang. Writing-original draft: L. Wang. Writing-review \& editing: G. Wu.

\section{Acknowledgments}

This work was supported by grants from the National Natural Science Foundation of China (grant no. 31072060) and the Science and Technology Major Project of Qinghai (Grant No. 2015-NK-A3). The authors would like to thank members of the Animal Nutrition Laboratory in Qinghai University, for providing instrumental testing services and technical assistance.

\section{References}

Anjum, M. I.; Khan, A. G.; Azim, A. and Afzal, M. 2005. Effect of dietary supplementation of multi-strain probiotic on broiler growth performance. Pakistan Veterinary Journal 25:25-29.

Al-Sultan, S. I.; Abdel-Raheem, S. M.; El-Ghareeb, W. R. and Mohamed, M. H. 2016. Comparative effects of using prebiotic, probiotic, synbiotic and acidifier on growth performance, intestinal microbiology and histomorphology of broiler chicks. Japanese Journal of Veterinary Research 64(Suppl 2):S187-S195.

Attia, Y. A. 2003. Performance, carcass characteristics, meat quality and plasma constituents of meat type drakes fed diets containing different levels of lysine with or without a microbial phytase. Archives of Animal Nutrition 57:39-48.

Attia, Y. A.; El-Tahawy, W. S.; Abd El-Hamid, A. E.; Nizza, A.; Al-Harthi, M. A.; El-Kelway, M. I. and Bovera, F. 2014. Effect of feed form, pellet diameter and enzymes supplementation on carcass characteristics, meat quality, blood plasma constituents and stress indicators of broilers. Archives of Animal Breeding 57:30. https://doi.org/10.7482/0003-9438-57-030

Attia, Y. A.; Bovera, F.; Abd El-Hamid, A. E.; Tag El-Din, A. E.; Al-Harthi, M. A. and El-Shafy, A. S. 2016. Effect of zinc bacitracin and phytase on growth performance, nutrient digestibility, carcass and meat traits of broilers. Journal of Animal Physiology and Animal Nutrition 100:485-491. https://doi.org/10.1111/jpn.12397

Aureli, R.; Faruk, M. U.; Cechova, I.; Pedersen, P. B.; Elvig-Joergensen, S. G.; Fru, F. and Broz, J. 2011. The efficacy of a novel microbial 6-phytase expressed in Aspergillus oryzae on the performance and phosphorus utilization in broiler chickens. International Journal of Poultry Science 10:160-168. https://doi.org/10.3923/ijps.2011.160.168

Balamurugan, R. and Chandrasekaran, D. 2010. Effect of multienzyme supplementation on weight gain, feed intake, feed efficiency and blood glucose in broiler chickens. Indian Journal of Science and Technology 3:193-195.

Bueno, R. D.; Borges, L. L.; God, P. I. V. G.; Piovesan, N. D.; Teixeira, A. I.; Cruz, C. D. and Barros, E. G. 2018. Quantification of anti-nutritional factors and their correlations with protein and oil in soybeans. Anais da Academia Brasileira de Ciências 90:205-217. https://doi.org/10.1590/0001-3765201820140465

Cabello, F. C. 2004. Antibiotics and aquaculture in Chile: implications for human and animal health. Revista Medica de Chile 132:1001-1006.

Cabello, F. C. 2006. Heavy use of prophylactic antibiotics in aquaculture: a growing problem for human and animal health and for the environment. Environmental Microbiology 8:1137-1144. https://doi.org/10.1111/j.1462-2920.2006.01054.x

Choo, Y. K.; Kwon, H. J.; Oh, S. T.; Um, J. S.; Kim, B. G.; Kang, C. W.; Lee, S. K. and An, B. K. 2014. Comparison of growth performance, carcass characteristics and meat quality of Korean local chickens and silky fowl. Asian-Australasian Journal of Animal Sciences 27:398-405. https://doi.org/10.5713/ajas.2013.13638

Cowieson, A. J.; Ptak, A.; Mackowiak, P.; Sassek, M.; Pruszynska-Oszmalek, E.; Zyla, K.; Swiatkiewicz, S.; Kaczmarek, S. and Jozefiak, D. 2013. The effect of microbial phytase and myo-inositol on performance and blood biochemistry of broiler chickens fed wheat/corn-based diets. Poultry Science 92:2124-2134. https://doi.org/10.3382/ps.2013-03140

Dawson, B. and Trapp, R. G. 2001. Basic and clinical biostatistics. 3rd ed. Lange Medical Books McGraw-Hill Medical Publishing Division, New York.

Fernandes, V. O.; Costa, M., Ribeiro, T.; Serrano, L.; Cardoso, V.; Santos, H.; Lordelo, M.; Ferreira, L. M. A. and Fontes, C. M. G. A. 2016. 1, 3-1, 4- $\beta$-Glucanases and not 1, 4- $\beta$-glucanases improve the nutritive value of barley-based diets for broilers. Animal Feed Science and Technology 211:153-163. https://doi.org/10.1016/j.anifeedsci.2015.11.007

Galdeano, C. M.; de Moreno de LeBlanc, A.; Vinderola, G.; Bonet, M. E. B. and Perdigon, G. 2007. Proposed model: Mechanisms of immunomodulation induced by probiotic bacteria. Clinical and Vaccine Immunology 14:485-492. https://doi.org/10.1128/CVI.00406-06

Gupta, R. K.; Gangoliya, S. S. and Singh, N. K. 2015. Reduction of phytic acid and enhancement of bioavailable micronutrients in food grains. Journal of Food Science and Technology 52:676-684. https://doi.org/10.1007/s13197-013-0978-y 
Humer, E.; Schwarz, C. and Schedle, K. 2015. Phytate in pig and poultry nutrition. Journal of Animal Physiology and Animal Nutrition 99:605-625. https://doi.org/10.1111/jpn.12258

Iji, P. A.; Hughes, R. J.; Choct, M. and Tivey, D. R. 2001. Intestinal structure and function of broiler chickens on wheat-based diets supplemented with a microbial enzyme. Asian-Australasian Journal of Animal Sciences 14:54-60. https://doi.org/10.5713/ajas.2001.54

Jaroni, D.; Scheideler, S. E.; Beck, M. M. and Wyatt, C. 1999. The effect of dietary wheat middlings and enzyme supplementation II: apparent nutrient digestibility, digestive tract size, gut viscosity, and gut morphology in two strains of leghorn hens. Poultry Science 78:1664-1674. https://doi.org/10.1093/ps/78.12.1664

Józefiak, D.; Ptak, A.; Kaczmarek, S.; Mackowiak, P.; Sassek, M. and Slominski, B. A. 2010. Multi-carbohydrase and phytase supplementation improves growth performance and liver insulin receptor sensitivity in broiler chickens fed diets containing full-fat rapeseed. Poultry Science 89:1939-1946. https://doi.org/10.3382/ps.2010-00694

Kalavathy, R.; Abdullah, N.; Jalaludin, S. and Ho, Y. W. 2003. Effects of Lactobacillus cultures on growth performance, abdominal fat deposition, serum lipids and weight of organs of broiler chickens. British Poultry Science 44:139-144. https://doi.org/10.1080/0007166031000085445

Kashani, S.; Mohebbifar, A.; Habibian, M. and Torki, M. 2014. Effects of phytase supplementation of low protein diets on performance, egg quality traits and blood biochemical parameters of laying hens. Annual Research \& Review in Biology 4:684-698. https://doi.org/10.9734/ARRB/2014/4444

Kies, A. K.; Gerrits, W. J. J.; Schrama, J. W.; Heetkamp, M. J. W.; van der Linden, K. L.; Zandstra, T. and Verstegen, M. W. A. 2005. Mineral absorption and excretion as affected by microbial phytase, and their effect on energy metabolism in young piglets. The Journal of Nutrition 135:1131-1138. https://doi.org/10.1093/jn/135.5.1131

Lei, X.; Piao, X.; Ru, Y.; Zhang, H.; Péron, A. and Zhang, H. 2015. Effect of Bacillus amyloliquefaciens-based direct-fed microbial on performance, nutrient utilization, intestinal morphology and cecal microflora in broiler chickens. AsianAustralasian Journal of Animal Sciences 28:239-246. https://doi.org/10.5713/ajas.14.0330

Liu, N.; Ru, Y. J. and Li, F. D. 2009. Effect of dietary phytate and phytase on metabolic change of blood and intestinal mucosa in chickens. Journal of Animal Physiology and Animal Nutrition 94:368-374. https://doi.org/10.1111/j.14390396.2009.00917.x

Lopez, H. W.; Leenhardt, F.; Coudray, C. and Remesy, C. 2002. Minerals and phytic acid interactions: is it a real problem for human nutrition? International Journal of Food Science and Technology 37:727-739. https://doi.org/10.1046/j.13652621.2002.00618.x

Maisonnier, S.; Gomez, J. and Carré, B. 2001. Nutrient digestibility and intestinal viscosities in broiler chickens fed on wheat diets, as compared to maize diets with added guar gum. British Poultry Science 42:102-110. https://doi. org/10.1080/00071660020035154

Mansoub, N. H. 2010. Effect of probiotic bacteria utilization on serum cholesterol and triglycerides contents and performance of broiler chickens. Global Vet 5:184-186.

Mappley, L. J.; Tchórzewska, M. A.; Nunez, A.; Woodward, M. J.; Bramley, P. M. and La Ragione, R. M. 2013. Oral treatment of chickens with Lactobacillus reuteri LM1 reduces Brachyspira pilosicoli-induced pathology. Journal of Medical Microbiology 62:287-296. https://doi.org/10.1099/jmm.0.051862-0

Mathlouthi, N.; Lallès, J. P.; Lepercq, P.; Juste, C. and Larbier, M. 2002. Xylanase and $\beta$-glucanase supplementation improve conjugated bile acid fraction in intestinal contents and increase villus size of small intestine wall in broiler chickens fed a rye-based diet. Journal of Animal Science 80:2773-2779. https://doi.org/10.2527/2002.80112773x

Mehr, M. A.; Shargh, M. S.; Dastar, B.; Hassani, S. and Akbari, M. R. 2007. Effect of different levels of protein and Protexin on broiler performance. International Journal of Poultry Science 6:573-577. https://doi.org/10.3923/ijps.2007.573.577

Mondal, M. K.; Panda, S. and Biswas, P. 2007. Effect of microbial phytase in soybean meal based broiler diets containing low phosphorous. International Journal of Poultry Science 6:201-206. https://doi.org/10.3923/ijps.2007.201.206

Montagne, L.; Pluske, J. R. and Hampson, D. J. 2003. A review of interactions between dietary fibre and the intestinal mucosa, and their consequences on digestive health in young non-ruminant animals. Animal Feed Science and Technology 108:95-117. https://doi.org/10.1016/S0377-8401(03)00163-9

Mosca, F.; Kuster, C. A.; Stella, S.; Farina, G.; Madeddu, M.; Zaniboni, L. and Cerolini, S. 2016. Growth performance, carcass characteristics and meat composition of Milanino chickens fed on diets with different protein concentrations. British Poultry Science 57:531-537. https://doi.org/10.1080/00071668.2016.1174768

NRC - National Research Council. 1994. Nutrient requirements of poultry. NRC, Washington, DC, USA.

Pan, X.; Qiang, Z.; Ben, W. and Chen, M. 2011. Residual veterinary antibiotics in swine manure from concentrated animal feeding operations in Shandong Province, China. Chemosphere 84:695-700. https://doi.org/10.1016/j. chemosphere.2011.03.022

Pourakbari, M.; Seidavi, A.; Asadpour, L. and Martínez, A. 2016. Probiotic level effects on growth performance, carcass traits, blood parameters, cecal microbiota, and immune response of broilers. Anais da Academia Brasileira de Ciências 88:1011-1021. https://doi.org/10.1590/0001-3765201620150071

R. Bras. Zootec., 48:e20180273, 2019 
Rasmussen, A. J. and Andersson, M. 1996. New method for determination of drip loss in pork muscles. In: Proceedings of the 42nd International Congress of Meat Science and Technology, Lillehammer, Norway. p.286-287.

Santin, E.; Maiorka, A.; Macari, M.; Grecco, M.; Sanchez, J. C.; Okada, T. M. and Myasaka, A. M. 2001. Performance and intestinal mucosa development of broiler chickens fed diets containing Saccharomyces cerevisiae cell wall. The Journal of Applied Poultry Research 10:236-244. https://doi.org/10.1093/japr/10.3.236

Stephens, T. P.; Stanford, K.; Rode, L. M.; Booker, C. W.; Vogstad, A. R.; Schunicht, O. C.; Jim, G. K.; Wildman, B. K.; Perrett, T. and McAllister, T. A. 2010. Effect of a direct-fed microbial on animal performance, carcass characteristics and the shedding of Escherichia coli 0157 by feedlot cattle. Animal Feed Science and Technology 158:65-72. https://doi.org/10.1016/j.anifeedsci.2010.04.007

Suo, C.; Yin, Y.; Wang, X.; Lou, X.; Song, D.; Wang, X. and Gu, Q. 2012. Effects of Lactobacillus plantarum ZJ316 on pig growth and pork quality. BMC Veterinary Research 8:89. https://doi.org/10.1186/1746-6148-8-89

Villanueva, A. P.; Ebling, P. D.; Pontalti, G. C. and Ribeiro, A. M. L. 2016. Effect of incubation system on the development of intestinal villi, metabolism, and performance of one-to forty-day-old broiler chickens. Revista Brasileira de Zootecnia 45:524-531. https://doi.org/10.1590/s1806-92902016000900004

Wang, L.; Yang, Y.; Cai, B.; Cao, P.; Yang, M. and Chen, Y. 2014. Coexpression and secretion of endoglucanase and phytase genes in Lactobacillus reuteri. International Journal of Molecular Sciences 15:12842-12860. https://doi.org/10.3390/ijms150712842

Wu, Y. B.; Ravindran, V.; Thomas, D. G.; Birtles, M. J. and Hendriks, W. H. 2004. Influence of phytase and xylanase, individually or in combination, on performance, apparent metabolisable energy, digestive tract measurements and gut morphology in broilers fed wheat-based diets containing adequate level of phosphorus. British Poultry Science 45:76-84. https://doi.org/10.1080/00071660410001668897

Xu, Z. R.; Hu, C. H.; Xia, M. S.; Zhan, X. A. and Wang, M. Q. 2003. Effects of dietary fructooligosaccharide on digestive enzyme activities, intestinal microflora and morphology of male broilers. Poultry Science 82:1030-1036. https://doi.org/10.1093/ps/82.6.1030

Zhang, A. W.; Lee, B. D.; Lee, S. K.; Lee, K. W.; An, G. H.; Song, K. B. and Lee, C. H. 2005. Effects of yeast (Saccharomyces cerevisiae) cell components on growth performance, meat quality, and ileal mucosa development of broiler chicks. Poultry Science 84:1015-1021. https://doi.org/10.1093/ps/84.7.1015

Zhou, X.; Wang, Y.; Gu, Q. and Li, W. 2010. Effect of dietary probiotic, Bacillus coagulans, on growth performance, chemical composition, and meat quality of Guangxi Yellow chicken. Poultry Science 89:588-593. https://doi.org/10.3382/ps.2009-00319 